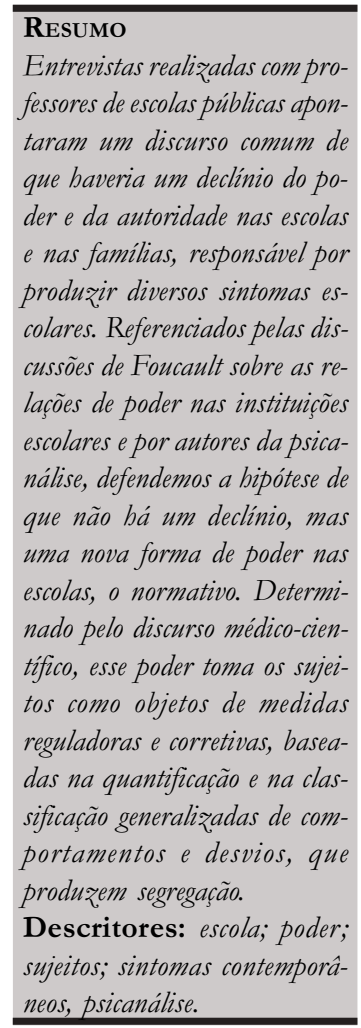

\section{O PODER NORMATIVO NAS ESCOLAS E SEUS EFEITOS SOBRE OS SUJEITOS}

\author{
Nádia Laguárdia de Lima \\ Alice Oliveira Rezende
}

\title{
Introdução
}

$\mathbb{E}_{4}$ ste artigo apresenta uma reflexão teórica sobre o declínio da autoridade na atualidade, em especial, no campo da educação escolar. $\mathrm{O}$ interesse pelo tema surgiu a partir de entrevistas realizadas por alunos de graduação em Psicologia com quinze professores

Psicanalista, professora adjunta do Departamento de Psicologia e do Programa de PósGraduação em Psicologia da Universidade Federal de Minas Gerais (UFMG), Belo Horizonte, MG, Brasil.

- Aluna de graduação em Psicologia e do projeto de Iniciação Científica "Os adolescentes na internet: os laços sociais via Orkut e seus efeitos sobre os adolescentes", da Universidade Federal de Minas Gerais (UFMG), Belo Horizonte, MG, Brasil. 
da rede pública do Ensino Fundamental, como parte de um trabalho de campo, vinculado à disciplina Psicologia Escolar. As entrevistas tinham dois objetivos centrais: investigar as maiores dificuldades encontradas pelos professores em suas práticas docentes e os motivos que eles elegem para essas dificuldades. Identificamos duas principais queixas dos professores com relação aos alunos: uma relacionada ao comportamento escolar e outra ao desinteresse pela aprendizagem. Ao buscarem explicações para essas dificuldades, houve uma ênfase na responsabilização da família, apesar de considerarem a presença dos fatores sociais, políticos e econômicos na produção dos sintomas escolares. A maioria dos professores acredita que há um declínio "do poder" dos pais, da escola e dos professores sobre as crianças e os adolescentes na atualidade. Como tentativa de solução, buscam, muitas vezes, medidas para reforçar o controle sobre os alunos.

A partir da teoria de Foucault (1994) sobre a sociedade disciplinar e de autores psicanalistas que analisam a contemporaneidade, defendemos a hipótese de que não há um declínio do poder na época atual, mas sim uma nova forma de poder, que se infiltra nas escolas, com efeitos segregativos sobre os sujeitos.

\section{O poder disciplinar em Foucault}

Para Foucault (1994), com o declínio da monarquia, o poder majestático deslocou-se para os próprios indivíduos. No ocidente moderno, o poder não mais é operado pela coerção externa e eventual, mas de modo contínuo e vigilante. Ele se deslocou do soberano e espalhou-se pela sociedade, através das normas, nas instituições. A sociedade disciplinar constitui-se de poderes transversais, que operam por meio das instituições modernas e de estratégias de disciplina e confinamento.

$\mathrm{Na}$ modernidade, as práticas disciplinares, como técnicas de exercício de poder, voltavam-se contra o indivíduo e seu corpo, para a sua normalização e adestramento mediante as diversas instituições que esse indivíduo atravessava durante a sua vida. As práticas disciplinares visavam a docilizar os corpos para serem aptos à produção industrial, integrando-os em sistemas de controle eficazes e econômicos. 
A aparente liberdade de direitos defendida pela modernidade escondia, pois, uma grande vigilância. $\mathrm{O}$ poder se constituiu como uma instância invisível, que passou a ser interiorizada e sujeitada à consciência moral. O indivíduo disciplinado é ordenado a partir de uma norma, que determina a sua filiação ou não à normalidade. Ele é visado como um objeto determinado, diferenciado e dotado de uma interioridade, sendo o alvo do cuidado dos Estados e de uma série de agências privadas.

O poder disciplinar iniciou-se no séc. XVII como "a arte do bom adestramento", instaurando-se como um poder modesto que produz indivíduos adaptados ao funcionamento das engrenagens maiores do sistema social vigente. $O$ poder disciplinar estrutura, dentre uma série de instituições sociais, a escola, também chamada por Foucault (1994) de "casa de educação".

O poder disciplinar constituiu-se como um método de extração das forças dos sujeitos, objetalizando-os e instrumentalizando-os simultaneamente, visando, em última instância, ao funcionamento da máquina social. A disciplina passou a ser exercida através do "olhar hierárquico", da "sanção normalizadora" e da junção destes no "procedimento examinatório". Discutiremos esses três instrumentos do poder disciplinar, relacionando-os com a contemporaneidade e com os discursos dos professores entrevistados.

\section{O poder do olhar}

Foucault (1994) descreve uma mudança de paradigma espacial, da época clássica para a moderna, marcada pela construção dos "observatórios humanos", com o objetivo de instaurar a disciplina. O poder disciplinar era simbolizado pela arquitetura do pan-óptico, concebido por Bentham como um projeto de prisão circular, em que um único observador podia ver todos os locais onde houvesse presos. De acordo com Foucault, "o dispositivo panóptico organiza unidades espaciais que permitem ver sem parar e reconhecer imediatamente" (p. 177). Para o autor, o efeito mais importante do pan-óptico é induzir no detento um estado consciente e permanente de visibilidade que assegura o funcionamento automático do poder.

O edifício da escola é também um operador de adestramento (Foucault, 1994, p. 155). O olhar hierárquico é determinante no projeto arquitetônico da escola, serve ao jogo de espelhos, próprio ao jogo de olhares, em que os indivíduos passam a se vigiar uns aos outros. O controle dos corpos é discreto, é feito por olhares que veem sem ser vistos.

Tais técnicas mostraram-se muito mais eficientes justamente por funcionarem como parte da estrutura institucional, sendo dificilmente apreendidas ou delimitadas, confundindo o aluno e a escola e provocando uma 
visibilidade geral no espaço da escola. Para Foucault (1994), a arquitetura tem como objetivo "agir sobre aquele que abriga, dar domínio sobre seu comportamento, reconduzir até eles os efeitos do poder, oferecê-los a um conhecimento, modificá-los" (p. 155).

A vigilância hierarquizada, contínua e funcional apresenta-se como uma das grandes invenções do séc. XVIII. As arquiteturas circulares expressam o funcionamento de um ideal político ao qual "nada escapa", uma ordem que advém de cima para baixo, mas que funciona lateral e transversalmente. Trata-se de concentrar em um único ponto o controle de todo o espaço e, principalmente, de todos os que ocupam determinado espaço. A partir de então, há uma reestruturação das organizações sociais, fazendo-se necessário incluir a função de vigilante na própria estrutura. $\mathrm{O}$ vigia não está nem do lado de fora nem do lado de dentro: "é ao mesmo tempo uma peça interna no aparelho de produção e uma engrenagem específica do poder disciplinar" (Foucault, 1994, p. 157).

Se os palácios eram feitos para serem vistos e para vigiar o espaço exterior, a disciplina trata de que os vigias sejam, na mesma medida, vigiados. A arte obscura do tornar visível implica todo um aparato tecnológico para sujeitar e utilizar o homem. $\mathrm{O}$ sistema de engrenagem funciona pela definição cada vez mais específica do lugar de cada sujeito, sendo claramente exemplificado nas instituições escolares, como demonstra Foucault:
Mesmo movimento na reorganização do ensino elementar: especificação da vigilância e integração à relação pedagógica. O mestre passa a determinar aos melhores alunos diversas funções como intendentes, monitores, repetidores, recitadores de orações, oficiais de escrita, recebedores de tinta, capelães e visitadores. (1994, p. 157)

O sucesso desse dispositivo se dá graças à sua articulação à economia e aos fins políticos onde é exercido, entrelaçando o tripé: ensino, aquisição de conhecimentos através da pedagogia e uma observação recíproca e hierarquizada, que sustenta a escola. A vigilância opera como um dispositivo intrínseco ao ensino, tecendo uma rede de fiscais que se fiscalizam perpetuamente.

A sociedade deixou de ser essencialmente jurídica, sob a égide da lei, para tornar-se uma sociedade articulada essencialmente sob a norma; regida por um sistema de vigilância que não se faz mais pelo Estado, mas por uma visibilidade incessante, na qual os próprios indivíduos se oferecem espontaneamente para serem vigiados ou avaliados.

O pan-óptico é uma figura de tecnologia política, um tipo de implantação de corpos no espaço, de organização hierárquica, de disposição de centros de poder, um esquema que pode ser utilizado nos hospitais, escolas, prisões, oficinas. Em cada uma de suas aplicações, permite aperfeiçoar o exercício do poder. Assim, esse esquema estendeu-se para as mais diversas instituições, com o ob- 
jetivo de observar, fazer experimentos e controlar o comportamento das pessoas. Segundo Foucault (1994), sua força é nunca intervir, é se exercer espontaneamente e sem ruído, é constituir um mecanismo de efeitos em cadeia. É o princípio geral de uma nova anatomia política cujo objeto e fim não são a relação de soberania, mas as relações de disciplina (p. 184).

Enquanto na modernidade o poder disciplinar atuava dentro das instituições, que apresentavam seus limites bem claros e definidos, na pós-modernidade o controle passou gradativamente de uma esfera local para todos os domínios da sociedade, sendo exercido e aperfeiçoado através de uma série de dispositivos tecnológicos.

Houve uma ramificação dos mecanismos disciplinares, uma tendência a se desinstitucionalizar, a sair das fortalezas fechadas (Foucault, 1994). Para Deleuze (1992), com a crise das instituições disciplinares e com o avanço das tecnologias da imagem e da informação, teríamos passado da sociedade disciplinar para a sociedade do controle, uma espécie de controle aberto e contínuo. No entanto, acreditamos que a sociedade disciplinar não foi superada. Pelo contrário, os mecanismos disciplinares estão cada vez mais eficientes, saíram dos muros institucionais e alcançaram todos os espaços sociais. Nessa sociedade, o poder atinge uma dimensão extraterritorial. Os mecanismos de dominação são interiorizados. A sociedade capitalista global orienta-se para uma sociedade de informação, em rede, difundindo de maneira plástica, móvel e fugidia a dominação. Nessas redes, o domínio deixa de ser exterior e opera no íntimo da subjetividade (Motta, 2006). A civilização atual é a da visibilidade total, marcada pelas tecnologias da imagem, que sustentam a ilusão de que tudo pode ser visto e, fundamentalmente, a de que a verdade pode ser capturada por completo através do olhar.

Foucault (1988), ao discorrer sobre a história da sexualidade, descreve o biopoder que vem integrar-se à disciplina. Se a disciplina age sobre os indivíduos, o biopoder, segundo Foucault, age sobre a espécie, "no corpo-espécie, no corpo transpassado pela mecânica do ser vivo e como suporte dos processos biológicos" (p. 152). O biopoder visa a alcançar toda a vida humana através de técnicas de poder sobre os processos biológicos, incluindo-se desde o nascimento, a mortalidade e a saúde da população até o controle de epidemias e da longevidade. O biopoder busca modificar o corpo, transformá-lo, aperfeiçoá-lo e produzir conhecimento sobre ele para melhor manejá-lo. Assim como o poder disciplinar, o biopoder é 
importante para o desenvolvimento do capitalismo na medida em que busca controlar a população e adequá-la aos processos econômicos.

O poder disciplinar e o biopoder associam-se, assegurando a constituição da sociedade normalizadora, cujos mecanismos de regulação e correção produzem, avaliam e classificam as "anomalias sociais". Podemos inferir que o olhar que vigia é utilizado hoje como um instrumento do biopoder, que se sustenta no discurso médico-científico. Vivemos sob a égide da biopolítica, o estilo de governo que regulamenta a população através do biopoder. Nessa sociedade normalizadora, os indivíduos são tomados como objetos de medidas reguladoras e corretivas, submetidos à quantificação generalizada dos comportamentos e dos desvios, classificados como normais ou patológicos (Foucault, 1988).

$\mathrm{O}$ avanço tecnológico fortalece o biopoder. As tecnologias biomédicas, as teorias genéticas e a epidemiologia dos fatores de risco defendem o controle sobre os corpos, a vida e a morte. A divulgação de pesquisas e "descobertas" pelos meios de comunicação alimenta a crença num corpo ideal, sem perdas, que pode esquivar-se do envelhecimento e da morte. Multiplicam-se os tratamentos, remédios, dietas, cirurgias, alimentos e "terapias" que prometem o controle dos corpos e da espécie.

No campo da "saúde mental", o mesmo acontece. As categorias classificatórias de transtornos mentais do Diagnostic and statistical manual of mental disorders (DSM) e da Classification of mental and behavioural disorders: Clinical descriptions and diagnostic guidelines (CID) transformam-se em verdadeiras epidemias e adquirem escala de massa, graças à sua propagação pela mídia. Os dispositivos tecnológicos facilitam a perpetuação do biopoder, divulgando saberes sobre o corpo e produzindo "transtornos" que retroalimentam esse tipo de poder.

No espaço escolar, os professores exercem vigilância constante sobre os corpos que se movimentam fora de seus "controles", encaminhando os alunos para os serviços médicos, em substituição aos antigos encaminhamentos feitos aos psicólogos. Professores, funcionários da escola, pais e até mesmo os próprios alunos estão "atentos" à possibilidade de um "diagnóstico precoce" dos distúrbios de comportamento, para que se possa agir rapidamente sobre o corpo da criança, controlando-o. 
Alguns professores entrevistados disseram que precisam atualizar-se com relação aos transtornos psicológicos e psiquiátricos para poderem diagnosticar e encaminhar precocemente as crianças com problemas, que proliferam nas escolas. Essa multiplicação de "crianças-problema" nas escolas não atestaria uma falha do próprio processo educativo?

\section{A sanção normalizadora e o poder normativo}

A segunda técnica do poder disciplinar, a sanção normalizadora, é um simulacro em menor escala do mecanismo penal. A aplicação da lei se faz através da aplicação de uma punição, tendo como efeito retroativo uma sociedade autorregulável e como produto a homogeneização dos sujeitos. Portanto, os comportamentos desviantes precisam ser castigados para serem corrigidos.

As sanções normalizadoras operam através do par puniçãoobrigação, em que a presença de um mecanismo determina a ausência do outro. Como salienta Foucault (1988), o que a punição pretende diante da recusa à norma é o retorno da lei com força duplicada. As estratégias religiosas de expiação e arrependimento assumem um lugar acessório na regulação dos sujeitos, marcando a idade moderna pela ascensão do Estado e o início do declínio da autoridade religiosa.

$\mathrm{Na}$ escola há uma micropenalidade do tempo, da atividade, da maneira de ser, dos discursos, do corpo e da sexualidade. A atmosfera é de uma universalidade punível-punidora. Foucault aponta o caráter paradoxal dos castigos disciplinares, que se orientam artificialmente através da ficção da norma e, ao mesmo tempo, definem-se por processos naturais e observáveis, como a duração do aprendizado em cada fase, o nível de aptidão, etc., que seguem uma regra. Assim, a punição comporta uma dupla referência, jurídico-natural.

Foucault (1994) questiona se a norma seria a nova lei da sociedade moderna. O normal se estabelece como princípio da coerção no ensino, com a instauração de uma educação estandardizada e a criação das escolas ditas normais. Mesmo na atualidade, as escolas "inclusivas" funcionam dentro dessa lógica normativa, 
e os alunos com "necessidades especiais" permanecem "estranhos" ao ambiente escolar, sendo excluídos dentro dele.

A punição-obrigação se insere no pano de fundo do par punição-recompensa. Essa lógica sustenta de certo modo algumas técnicas de "tratamento" e de organização das instituições. Sem nos estender nessa questão, perguntamo-nos acerca dessa prática e de sua relação com a avaliação e com o tratamento dos sintomas contemporâneos, dos "desajustes" que escapam às normas. Para além da justiça penal, a qualificação moral dos comportamentos como bons ou maus toma a cena do certo e errado que organiza uma microeconomia de privilégios e castigos.

Eis o que talvez possa ser considerado o exemplo mais típico. Estamos diante de uma epidemia daquilo que o DSM classificou como Transtorno de Deficit de Atenção e Hiperatividade (TDAH) em crianças, considerado pela sociedade norteamericana como um problema de saúde pública em função de sua prevalência, dos danos na performance escolar e social, dos custos para a economia, de sua cronicidade e dos limites das intervenções adotadas até o momento (Mandil, 2006).

Cabe ressaltar a imprecisão desse diagnóstico. Até hoje há controvérsias com relação à sua etiologia e, inclusive, com relação à sua existência, o que, por si só, deveria justificar 
um maior cuidado na prescrição de remédios para o seu tratamento. "O único quadro sintomático em que se apoiam os médicos para detectar a hiperatividade é o comportamento" (Stiglitz, 2006). Não existe nenhum exame laboratorial que comprove qualquer anomalia no organismo. O diagnóstico clínico se dá a partir de relatórios que são preenchidos por pais e professores sobre o comportamento dos alunos. O risco de reduzir o malestar ao campo da biologia é desconsiderar uma série de outros fatores, subjetivos e sociais, que podem ser responsáveis por sua produção. Além disso, o tratamento indicado apoia-se numa concepção deficitária do sintoma, desresponsabilizando o sujeito, com efeitos de segregação.

Para a criança-sujeito que sofre de TDAH, muitas vezes são impostos tratamentos comportamentais e medicamentosos que operam na lógica binária da sanção normalizadora. Alguns professores entrevistados utilizaram essas designações para nomear os "alunos-problema". Os diagnósticos de autismo, hiperatividade e TDAH são utilizados por alguns professores de forma indiscriminada para designar alunos que apresentam dificuldades de socialização ou de comportamento. Da qualificação dos comportamentos, segue-se sua quantificação, instrumento que permite o estabelecimento do balanço de cada indivíduo. A quantificação dos atos bons e maus resulta na hierarquização dos próprios indivíduos, ou seja, de "sua natureza” e não de seus atos. A mídia destaca frequentemente o alívio que a descoberta do diagnóstico provoca nas crianças e adolescentes, pois deixam de ser designados como "preguiçosos" e passam a ser compreendidos como "doentes". Interrogamos que alívio poderia advir dessa nova designação e a quem ela serve.

A escola hoje não avalia "a produção" do aluno, a sua prova ou o seu trabalho escolar, mas sim "o aluno". Os professores entrevistados disseram que, nas reuniões de equipe que ocorrem nas escolas, eles conversam sobre os alunos, fazendo uma “avaliação global” de cada um. Essa avaliação global leva em consideração a personalidade, a sociabilidade, a responsabilidade, o esforço pessoal, o capricho, a obediência, dentre outros aspectos "subjetivos". A partir dessa avaliação "pretensamente global”, eles decidem pela aprovação ou reprovação de um aluno que não obteve nota suficiente para ser aprovado. $\mathrm{O}$ aluno 
pode ser punido ou recompensado de acordo com os critérios "subjetivos" analisados pelos professores. $\mathrm{O}$ indivíduo é, pois, avaliado pela sua "natureza", não pelos seus atos.

A sanção de determinados sujeitos, sua hierarquização, visa à sua classificação como meio de ordenação, e esse próprio sistema vale como recompensa ou punição. Assim, o mérito e o comportamento são os únicos critérios que definem o lugar do aluno. A classificação que pune tende a ser substituída por aquela que segrega. Podemos inferir que aqueles que não se adéquam ao modelo determinado de "saúde" são retirados de "uma classe" para serem reintroduzidos em outra, a dos "doentes".

Recente pesquisa realizada na UFMG (Lima, 2010) revelou que as redes sociais virtuais, como Orkut, Facebook e Twitter, são instrumentos amplamente utilizados pela grande maioria dos adolescentes, havendo também uma crescente adesão de crianças. Nessas redes sociais, multiplicam-se as comunidades ou grupos formados a partir de "sintomas contemporâneos", como as comunidades de anoréxicos, bulímicos, hiperativos, deprimidos, dentre outras. Os jovens se oferecem "espontaneamente" para serem incluídos em categorias que funcionam como "camisas de força subjetivas" (Kehl, 2010), que os homogeneízam. Aplicativos nos celulares permitem que os jovens façam check-in de todos os lugares por onde passam, dispensando os vigias da épo- ca de Foucault. Os adolescentes se autovigiam e vigiam uns aos outros frequentemente pela Internet. A dimensão de sujeito parece muitas vezes excluída da aliança do homem com a tecnologia, ou incluída apenas a serviço do modo de produção capitalista.

O contexto atual se expressa sob a forma de uma sociedade de normalização, sobre a qual a medicina e a biologia incidem com a criação de mecanismos contínuos, reguladores e corretivos para cuidar da vida. No entanto, como salienta Mandil (2006), as próprias repartições classificatórias parecem desmanchar-se no ar, subdividindo-se infinitamente.

O TDAH, por exemplo, assume o estatuto de um problema de saúde pública justamente quando a infração, na ausência da lei, tende a sair do registro de uma transgressão, sendo absorvida pelo discurso médico-científico como uma desordem mental a ser identificada em termos populacionais e tratada pela medicina. Teixeira (2011) demonstra que a nosologia adotada pelo DSM e pela CID apoiase numa tipologia de convenções pautadas por uma abordagem descritivista que dissocia a classificação do esforço de teorização. Os sintomas são transformados em doenças, segundo os parâmetros de uma prática que se submete a avaliações de produtividade.

Uma evidência da vigilância contemporânea é o "Princípio de precaução" da sociedade das normas, com 
sua busca desenfreada de redução de riscos (Mandil, 2006). Segundo Mandil, nos Estados Unidos se encontra em operação o Sistema de Vigilância de Comportamentos de Risco em Jovens, monitorado pelo Departamento de Saúde do Governo Federal. O sistema foi construído a partir da constatação de que, no país, mais de $70 \%$ das mortes ocorridas entre jovens de 10 a 24 anos decorrem de quatro causas: acidentes de carro, outros tipos de acidente, homicídios e suicídios. O Sistema de Vigilância pretende monitorar “os comportamentos de risco" entre jovens, compreendendo um amplo espectro de seus hábitos. Um aspecto relevante desse sistema é o fato de não se limitar à saúde pública, mas de se estender aos objetivos educativos, sugerindo modificações curriculares e alterações na legislação.

Nessa mesma perspectiva, Tendlarz (2006) comenta que a maior expressão atual do empuxo à norma é o projeto de lei francês que, como modalidade de prevenção contra a delinquência, busca estabelecer um diagnóstico precoce através de um carnê de comportamento. O Transtorno Dissocial seria o antecedente dos "futuros criminosos". Sabemos dos riscos de um diagnóstico dado na infância, pois, ao invés de ter um efeito preventivo, pode, ao contrário, levar à identificação do sujeito com essa nomeação.

A contemporaneidade é marcada pela hegemonia do capital, tendo 
como efeito uma crise de sentido. Os objetos de consumo elevados ao zênite social representam um declínio dos valores simbólicos, que poderiam orientar os sujeitos. Ao mesmo tempo, multiplicamse as ofertas de identificação que visam a capturar os indivíduos, enquadrando-os em categorias segundo critérios médico-científicos pretensamente objetivos, que obedecem a interesses mercadológicos da indústria capitalista. Essas classificações exercem fascínio sobre as pessoas, que buscam enquadrar-se em alguma referência identificatória. A escola, mesmo tendo perdido o lugar social de instituição privilegiada na "transmissão do saber", exerce ainda importante função na formação e socialização das crianças e jovens. No entanto, ao se colocar como instrumento do discurso capitalista, ela transforma o saber em mercadoria e os alunos em objetos.

\section{O exame: a demissão do amor no discurso capitalista}

O terceiro modo de exercício do poder disciplinar descrito por Foucault é o exame interminável e a objetivação limitadora, que parecem reproduzir-se infinitamente na contemporaneidade. $\mathrm{O}$ exame articula as técnicas da hierarquia que vigia com as da sanção que normaliza, através de seu caráter altamente ritualizado, legitimando os modos de qualificação, classificação e punição.

O poderio do exame, sua cerimônia, organiza os sujeitos entre aqueles que são sujeitados como objetos e a objetivação dos que se sujeitam como "força de trabalho", determinando o lugar e a função de cada um na estrutura social. Ao sobrepor as relações de poder e de saber, o exame possibilita e justifica medir e sancionar todos simultaneamente. Foucault (1994) revela o estatuto documental da máquina examinatória, que inaugura o aparelho de escrita como modo de formalização do indivíduo dentro de relações de poder, possibilitando à escola produzir um campo de saber sobre seu aluno para melhor aproveitar-se de suas qualidades e talentos.

O investimento político nas escolas e das escolas se faz então para se obter e constituir um saber. Assim, a injunção da escola examinatória inaugurou a pedagogia enquanto ciência, situação na qual os alunos estão comprometidos pelos documentos que os cap- 
tam e os fixam. Na época atual, multiplicam-se indefinidamente as categorias de classificação e mensuração dos alunos.

Para Teixeira (2011), a euforia atual pela mensuração e classificação implica a extinção do amor no discurso capitalista, em função do próprio processo de estruturação desse sistema, que leva à extinção da falta-a-ser. O rechaço do amor pelo capitalismo revela a impossibilidade de se estabelecer um padrão na escolha de objeto amoroso, padrão esse que o capitalismo tenta a todo custo forjar, para consumirmos todos os mesmos produtos, como destaca o autor:

Por isso dizemos, a propósito do furor contemporâneo das escalas avaliativas, que sua expansão requer a extinção do amor: a metria germina no deserto da filia. Nossa hipótese é que sua emergência em contexto historicamente datado, distante do diálogo platônico, deve-se à ascensão propriamente moderna do capitalismo enquanto modo de organização política estruturalmente avessa à dimensão amorosa. Pois é fato que se a burguesia, como desde cedo viram Marx e Engels, rasgou o véu do sentimentalismo feudal ao reduzir os vínculos humanos às simples relações monetárias, fazendo da dignidade humana um simples valor de troca, foi porque o discurso do capitalista que a suporta se define como recusa do amor através da foraclusão da castração. (p. 346)

A medicalização da educação é uma resposta aos critérios de normalidade impostos pelo biopoder, que exige que todos sejam avaliados. Como salienta Tendlarz (2006), a solução dos psicofármacos nos faz consumidores e nos impulsiona a nos apropriarmos da solução médica de forma indiscriminada, sem considerar cada caso em particular.

A avaliação é o nome da loucura social atual. Quem não se submete à avaliação é suspeito de negar-se a prestar contas de si. Lacan (1997) orienta a análise no sentido de produzir um movimento de implicação do sujeito com relação a si próprio e ao próprio sintoma. Como implicar o sujeito tomado como objeto pelo discurso científico, inserido em categorias generalistas e homogeneizantes?

\section{A psicanálise frente ao poder normativo nas escolas: autoridade $\mathrm{x}$ poder}

A educação está em crise. Nas escolas públicas e particulares, o desinteresse pelo conhecimento acadêmico, a inquietude, o desrespeito ao professor e o consumismo são alguns dos problemas mais comuns. Crianças e adolescentes não se submetem às regras, não conseguem ficar quietos ou não se concentram nas atividades escolares. Há um declínio da autoridade do professor, que não é 
mais a referência de identificação para os alunos.

Cabe aqui um breve comentário acerca da diferenciação que podemos fazer entre autoridade e poder, a partir das considerações de Foucault e das discussões psicanalíticas sobre o declínio da autoridade na modernidade. Existem distintas concepções de poder. Para Arendt (2000), o poder é inerente a qualquer comunidade política e resulta da capacidade humana para agir em conjunto, o que requer o consenso de muitos quanto a um curso comum de ação (p. 8). Para a autora, é a desintegração do poder que leva à violência, pela falta do consenso e da opinião favorável de muitos. Foucault (2006) reconhece esse aspecto do poder, mas, segundo o autor, certas relações de poder constituem um efeito de dominação (p. 223). Ele acrescenta que a rede constituída por certas relações de poder funciona de tal forma que quase não permite que se evidencie essa dominação. Para ele, a medicalização da saúde está ligada a uma série de processos sociais, de ordem econômica, e também a instituições e práticas de poder. $\mathrm{O}$ autor destaca a relação existente entre os jogos de poder e os "jogos de verdade" científicos: "Quem diz a verdade? Indivíduos que são livres, que organizam um certo consenso e se encontram inseridos em uma certa rede de práticas de poder e de instituições coercitivas" (p. 283).

Freud (1914/1996) discute a questão da autoridade a partir do exer- cício da função paterna, ressaltando a sua importância no domínio das pulsões e na formação dos ideais, permitindo o laço social. Para Freud, o supereu é a instância psíquica que assume o papel da autoridade do pai; o eu da criança acomoda-se ao papel da autoridade degradada do pai. O rigor do supereu, no entanto, é a própria agressividade do sujeito que retorna contra ele e não tem relação com a severidade do pai, ou seja, é estrutural, como esclarece Lacan (2003a): “A gulodice pela qual Freud denotou o supereu é estrutural - não é um efeito da civilização, mas um 'mal-estar' (sintoma) na civilização” (p. 528).

Lacan (1992) adverte que todo pai é carente em sua função de barrar o gozo e que essa carência é de estrutura. Há uma impossibilidade simbólica de tradução do gozo, um impossível de dizer, um furo na língua, que desperta angústia no sujeito. Diante do encontro do sujeito com esse impossível, o neurótico recorre ao pai, ele se orienta "em direção a um pai suposto saber um pouco acerca disso e, sobretudo, saber demonstrá-lo" (Lacadée, 2006, p. 8).

Lacan (1938/2003b) assinala como, no seio da família moderna conjugal, a autoridade não é mais sustentada pela "imago paterna", que se apresenta em declínio social. O descrédito da figura do pai como autoridade levou à descrença nos grandes ideais, colocando em questão a incidência da exceção paterna. Na sociedade capitalista global, é o campo do 
gozo que orienta o sujeito, e não o ideal. Estamos na época em que o "Outro não existe" (Miller, 2008).

$\mathrm{Na}$ atualidade, a autoridade familiar não constitui mais uma barreira sobre a qual se possa apoiar. O pai não é mais a exceção que oferece uma saída, um ponto de onde os filhos poderiam se ver como dignos de ser amados (Lacadée, 2006). A dissolução dos modelos familiares e a evolução do capitalismo levaram a um empuxo ao gozo, a um imperativo de gozar sempre mais e mais, em nome dos novos direitos que são o direito ao gozo ou o direito a consumir os objetos que vêm escamotear sua falta. As crianças e os jovens desconhecem a autoridade da palavra do $\mathrm{Ou}-$ tro e buscam a satisfação através dos instrumentos de gozo imediato, "curto-circuitando" a mediação do Outro.

Tanto em Lacan como em Arendt, a autoridade é abordada sob o ângulo da responsabilidade, como comenta Lacadée (2006). Para o autor, a autoridade não se apoia sobre um "poder" exterior e impessoal que é imposto ao sujeito, mas é questão de "presença" e de "saber fazer". A criança reveste o adulto, que lhe transmite um saber fazer, com as vestes da autoridade e do respeito (Lacadée, 2006). A autoridade implica, pois, uma presença responsável do Outro e depende da maneira pela qual a língua foi ofertada ao sujeito, no enlace entre o gozo e o saber. Podemos diferenciar a autoridade, tal como descrita acima, da relação de poder como forma de dominação. 
$\mathrm{Na}$ atualidade, os pais não mais assumem a responsabilidade pelo mundo que oferecem à criança. Eles não são mais o sujeito suposto saber (Lacadée, 2006). O professor também não é mais reconhecido como autoridade pelos alunos, como alguém que tem um "saber-fazer". Como medida contra a perda da autoridade, os professores buscam impor o poder através de diversos dispositivos de controle.

É o que assistimos na sociedade em geral. A insegurança generalizada por ela vivida alimenta a busca pelo controle, a "indústria da segurança". Uma série de equipamentos eletrônicos é produzida para a "segurança" das pessoas. Como salienta Cohen (2006), a rede discursiva tecida pelos laços sociais em que estamos presos ou conectados, por meio de suas malhas constituídas pelas promessas de gozo, faz de nós corpos manipulados pan-opticamente, ou seja, quase tudo pode ser resolvido pela máquina que nos olha: nas empresas, nas residências, no sexo, na televisão, nas ruas. Olhamos e somos olhados por todos.

As escolas têm os seus vigias, humanos e tecnológicos, que olham a todos. Para além da máquina que olha e vigia, o poder captura aquele que olha, para que ele possa controlar o que vê. Assistimos a uma disputa de poderes sobre as crianças, por parte do Estado, da família e da sociedade, que visa a classificá-las para designar como as instituições podem melhor servir-se delas. Proliferam-se as classificações diagnósticas que atendem ao mercado de consumo, com efeitos segregativos sobre os sujeitos.

\section{Considerações finais}

Frente à força do poder normativo que opera nas escolas, questionamos como o psicanalista pode atuar, abrindo uma brecha nesse saber "totalizante". São os próprios professores que nos apontam uma saída. Diante do aparente sucesso das classificações médicas, os professores entrevistados denunciam os "furos" dos tratamentos generalistas oferecidos a essas crianças e adolescentes, questionando a sua eficácia. A multiplicação de transtornos na contemporaneidade não tem favorecido nem facilitado a prática educativa. Os remédios, mesmo que acalmem alguns alunos, não têm despertado neles o desejo de saber. Os professores percebem que há uma di- 
mensão, para além do campo da biologia, que deve ser considerada. As classificações diagnósticas e os tratamentos puramente medicamentosos não aliviam a angústia diante do mal-estar contemporâneo que aflige a educação. Os professores pedem ajuda, dizem que a escola "precisa de psicólogos", pois eles não sabem o que fazer. É pela via do "não saber" que algo pode ser construído.

Ao manter o aluno na posição de objeto, o que a escola obtém como resposta é a violência. O aumento do "controle" nas escolas visa a reforçar o poder quando a autoridade é falha. No entanto, ele não consegue silenciar os sujeitos, que insistem em "ser ouvidos" através de seus sintomas escolares. Só a escuta da singularidade pode oferecer uma resposta ao fracasso da educação escolar.

A psicanálise orienta-se por uma ética. Para além do sintoma, o psicanalista busca alcançar o desejo do sujeito. Se o psicanalista pode oferecer alguma contribuição para o campo da educação, ela é, em última instância, o seu não saber. Contra esse empuxo à quantificação, à arbitrariedade diagnóstica e à homogeneização das pessoas, o psicanalista escuta "um a um", para que cada sujeito possa nomear o seu mal-estar de maneira própria, inventando uma solução singular para aquilo que o perturba e assumindo a responsabilidade pela sua vida.

POWER STANDARD IN SCHOOLS AND THEIR EFFECTS ON THE SUBJECTS

ABstract

Interviews with teachers from public schools showed a common discourse that there is a decline in the power and authority of schools and families, producing different symptoms at school. Based on Foucault's thought about power relations in schools and on psychoanalysis authors, we defend the hypothesis that there isn't a decline of power in schools today, but a new form of power, the normative one. Determined by the medical-scientific discourse, this power takes the subjects as objects of regulatory and corrective measures based on quantification and generalized classification of behaviors and deviations, which produce segregation.

Index terms: school; power; subjects; contemporary symptoms, psychoanalysis.

EL PODER NORMATIVO EN LAS ESCUELAS Y SUS EFECTOS SOBRE LOS SUJETOS

RESUMEN

Entrevistas con profesores de escuelas públicas mostraron un discurso común de que habría una disminución de poder y autoridad en las escuelas y las familias, produciendo diferentes sintomas 
en la escuela. Basados en las discusiones de Foucault sobre las relaciones de poder en las escuelas, y en autores del campo psicoanalítico, defendemos la bipótesis de que no hay una disminución del poder en las escuelas hoy en día, sino una nueva forma de poder, el normativo. Este poder, determinado por el discurso médico-científico, toma a los sujetos como objetos de medidas reglamentarias y correctivas, sometiéndolos a la cuantificación y clasificación generalizada de comportamientos y desviaciones, produciendo la segregación.

Palabras clave: escuela; poder; sujetos; sintomas contemporáneos, campo psicoanalítico.

\section{REFERÊNCIAS}

Arendt, H. (2000). Sobre a violência (A. Duarte, Trad.). Rio de Janeiro: Relume Dumará.

Cohen, R. H. P. (2006). A lógica do fracasso escolar: psicanálise e educação. Rio de Janeiro: Contra Capa Livraria.

Deleuze, G. (1992). Controle e devir. In G. Deleuze, Conversações (P. P. Pelbart, Trad., pp. 209-218). São Paulo: Editora 34.

Foucault, M. (1988). História da sexualidade: a vontade de saber (M. T. da C. Albuquerque, Trad.). Rio de Janeiro: Edições Graal.

Foucault, M. (1994). Vigiar e punir: história da violência nas prisões (R. Ramalhete, Trad.). Petrópolis: Vozes.

Foucault, M. (2006). Ética, sexualidade, politica (E. Monteiro \& I. A. D. Barbosa, Trad.). Rio de Janeiro: Forense.

Freud, S. (1996). Algumas reflexões sobre a psicologia do escolar. In S. Freud, Edição standard brasileira das obras psicológicas completas de Sigmund Freud (J. Salomão, Trad., Vol. 13, pp. 281-288). Rio de Janeiro: Imago. (Trabalho original publicado em 1914)

Khel, M. R. (2010). O tempo e o cão: a atualidade das depressões. São Paulo: Boitempo. Lacadée, P. (2006). A autoridade da língua. La Petite Girafe, 23, 7-15.

Lacan, J. (1992). O Seminário, livro 17: o avesso da psicanálise (A. Roitman, Trad.). Rio de Janeiro: Jorge Zahar.

Lacan, J. (1997). O Seminário, livro 7: a ética da psicanálise (A. Quinet, Trad.). Rio de Janeiro: Jorge Zahar.

Lacan, J. (2003a). Televisão. In J. Lacan, Outros escritos (V. Ribeiro, Trad., pp. 508543). Rio de Janeiro: Jorge Zahar.

Lacan, J. (2003b). Os complexos familiares na formação do indivíduo. In J. Lacan, Outros escritos (V. Ribeiro, Trad., pp. 29-90). Rio de Janeiro: Jorge Zahar. (Trabalho original publicado em 1938)

Lima, N. L. (2010). Adolescência, identificação e laço social nas redes sociais virtuais. Pesquisa realizada na UFMG e financiada pelo Programa Institucional de Auxílio à Pesquisa de Doutores Recém-Contratados da Pró-Reitoria de Pesquisa da UFMG.

Mandil, R. (2006). Biopolítica del déficit de atención. In G. Stiglitz (Org.), DDA, $A D D, A D H D$, como ustedes quieran: el mal real y la construcción social (pp. 91-98). Buenos Aires: Grama Ediciones. 
Miller, J.-A. (2008). El otro que no existe y sus comités de ética. Buenos Aires: Paidós. Motta, M. B. (2006). Apresentação. In M. Foucault, Ética, sexualidade, politica (E. Monteiro \& I. A. D. Barbosa, Trad., pp. V-LXII). Rio de Janeiro: Forense.

Stiglitz, G. (Org.). (2006). DDA, ADD, ADHD, como ustedes quieran: el mal real y la construcción social. Buenos Aires: Grama Ediciones.

Teixeira, A. (2011). A bibliofilia contra a bibliometria. Tempo psicanalitico, 43(2), 341-354. Recuperado em 12 de agosto, 2012, de PePSIC (Periódicos Eletrônicos em Psicologia): http://pepsic.bvsalud.org/scielo.php?pid=S010148382011000200006\&script=sci_arttext

Tendlarz, S. (2006). La atención que falta y la actividad que sobra. In G. Stiglitz (Org.), DDA, ADD, ADHD, como ustedes quieran: el mal realy la construcción social. Buenos Aires: Grama Ediciones.

nadia.laguardia@gmail.com

Av. Antonio Carlos, 6627

31270-901 - Belo Horizonte - MG - Brasil.

aliceorezende@gmail.com

Rua Grão Mogol, 162/600

30310-010 - Belo Horizonte - MG - Brasil.

Recebido em agosto/ 2012.

Aceito em novembro/ 2012.

52 Estilos clin., São Paulo, v. 18, n. 1, jan./abr. 2013, 34-52. 